\title{
Attitudes of Future Tourism Sector Employees Towards Organise Accessible Tourism
}

\author{
Alina Zajadacz \\ Adam Mickiewicz University in Poznań, Poznań, Poland
}

\begin{abstract}
The aim of this paper is to show a theoretical approach to the evolution of concepts perceiving disability, taking into account the medical, social, and geographical models, as the basis for the development of principles concerning the organisation of accessible tourism for people with disabilities (PwD). The main research objective was to identify the current attitudes of future, potential employees in the tourism (tourism and recreation students at the time of the study) towards accessible tourism. The study was based on surveys performed in May 2013 at the Adam Mickiewicz University in Poznań (UАМ, Poland) and the State University in Irkutsk (ИГУ, Russia), a total sample of 216 people. The main section of the survey contained four questions regarding issues such as: optimal ways to organise tourism products for people with a disability; attitudes towards spending leisure time together with people with a disability; and specific requirements concerning the introduction of various types of improvements in tourism products aimed at people with a disability. In both cases, the results revealed that future tourism employees hold attitudes which are prevailingly open and positive towards the needs of tourists with disabilities. However, the hypothesis that the main factor influencing a reluctance to enter into contact with $\mathrm{PwD}$ is a lack of experience in this area, resulting in insufficient knowledge of what conditions the behaviour of PwD was also confirmed. This is a highly significant conclusion which should consider if mandatory educational programmes in the field of tourism and recreation studies are to be improved.
\end{abstract}

Keywords: accessible tourism, medical model of disability, social model of disability, geographical model of disability, tourism services, tourism education

\section{Introduction}

Tourism is a manifestation of lifestyle and living standards within society. Its development is significantly affected by demographic changes, including the observed increase in the number of people with a disability which is also related to an ageing population. In Europe, it is estimated that there will be a threefold increase in the number of people aged 65 by 2050 as compared to 2003. There are currently around 75 million people with disabilities $(\mathrm{PwD})$ in the EU, which accounts for $15 \%$ of the overall population (European Union, Facts and Figures, 2012). The demographic changes taking place are a significant challenge for the tourism sector which is governed by legislation including, for example, the Convention on the Rights of Persons with Disabilities (2006), which states that PwD have the right to take part in recreational, tourism, leisure, and sporting activities

Alina Zajadacz, Ph.D., assistant professor, Department of Tourism and Recreation, Faculty of Geographical and Geological Sciences, Adam Mickiewicz University in Poznań, Poznań, Poland.

Correspondence concerning this article should be addressed to Alina Zajadacz, Department of Tourism and Recreation, Faculty of Geographical and Geological Sciences, Adam Mickiewicz University in Poznań, ul. Dziegielowa 27, 61-680 Poznań, Poland. 
on an equal basis with others. These changes bring about a gradual increase in the importance of the market of tourist services intended for disabled tourists in terms of yielding ever larger profits (economic effects) for the tourist sector. The scale of this phenomenon is illustrated by the 2002, 2005, and 2015 Market Study reports published by Open Doors (Lipp, 2015). The 2015 ODO study quantifies how much adults with disabilities spend on just their own travel- $\$ 17.3$ billion annually, up from $\$ 13.6$ billion in 2002 . Since these individuals typically travel with one or more other adults, the economic impact is actually double, or $\$ 34.6$ billion (Lipp, 2015).

Guaranteeing PwD's easy and independent access to tourism products is at the core of the "accessible tourism" concept which is understood as:

A form of tourism that involves collaborative processes among stakeholders that enable people with access requirements including mobility, vision, hearing, and cognitive dimensions of access to function independently and with equity and dignity through the delivery of universally designed tourism products, services, and environments. (Buhalis \& Darcy, 2011, pp. 11-12)

Broadly speaking, the concept of "accessibility" means the degree to which a given person can easily and independently access buildings and other sites including open areas without the need for special help (European Disability Strategy 2010-2020, 2010). In addition to guaranteeing the technical requirements of universal design standards, basic conditions for the development of accessible tourism include the expertise of tourism sector employees in relation to serve clients with disabilities. This includes incidental knowledge, skills, and personal characteristics (such as openness, creativity, and flexibility when searching for the best solutions). These aspects develop through personal experience as well as the different concepts of disability, conditioning any action undertaken.

The aim of the paper is to approach the assumptions of the disability models (medical, social, and geographical) as social conditions affecting the attitudes of future, potential employees in the tourism sector towards clients with a disability. It is against this theoretical background that the current attitudes of tourism and recreation students towards customer service in relation to $\mathrm{PwD}$, based on the survey results, are presented. The analysis incorporates the opinions of the surveyed students from Poland and Russia. The paper presents a synthesis of the research results discussed in more detail by Zajadacz (2014a), which on the one hand reveals a great openness of university students to solving problems relating to accessibility of tourism for PwD, but on the other hand points to certain hesitation in their contacts with disabled people, which-above all-results from a lack of experience and knowledge (how to behave properly?). The survey results show the students' opinions, i.e., they provide an answer to the question: "what is it like?", which is a starting point for searching for an answer to the question: "what should it be like?", so that the services provided for disabled tourists are professional and adapted to their individual needs. The conclusions are not only of cognitive significance, but also - first of all—of practical one, i.e. they can be followed when drawing up educational programmes in the field of tourism and recreational studies so as to include factors determining the development of accessible tourism. Their implementation can help provide tourist services with new and better quality.

\section{Literature Review}

"Disability is a complex phenomenon, reflecting an interaction between features of a person's body and features of the society in which he or she lives" (World Health Organization, 2011, p. 3). The perception of 
disability has evolved through time and a number of models defining concepts exist: medical, social, and geographical (Zajadacz, 2015).

The medical model of disability (MM model) was first submitted in 1951 by Parsons (1951). It assumes that disability is connected to the individual features of a given person and is above all their own personal tragedy (Parsons, 1951). Any action undertaken (medical treatment, rehabilitation) is aimed at maximising the ability of the individual (adaptation to the environment). This model has met with some criticisms due to the fact that its central focus is on the causes of disability (Best, 2010).

The social model of disability (SM model) is founded on opposing assumptions. The basic theory is that disability is not due to individual characteristics but is rather the result of existing restrictive factors in the environment (including social and mental barriers) which multiply the dysfunction of a given person and hinder or prevent participation in the full scope of life in society (Oliver, 1996; Darcy \& Pegg, 2011). There are both advantages and disadvantages to the SM model. A positive aspect is that it clearly highlights the necessity to introduce changes increasing accessibility, services, and participation in society for people with a disability. The passive treatment of PwD as "victims" of an inaccessible environment and social neglect is regarded as a weakness of this model and it is often an insufficient response to their needs.

An alternative to the models presented above is the geographical model of disability (GM model). This concept applies experience gathered to date (connected to the MM and SM models) and focuses mainly on the interrelation between PwD and geographical space (Zajadacz, 2014b). Geographers connect the nature of factors causing disability both with social and spatial aspects of the human environment, they promote solutions which are more "inclusive" and which provide access to sites and the full scope of life in society taking different degrees and types of disability into consideration (Chouinard, Hall, \& Wilton, 2010). Universal design should therefore take the nature of these needs into account in universal design, in the creation of maximally accessible buildings, sites, and public services (Imrie, 2012; Zajadacz, 2014c). The GM also aims to remove social "tensions" related to the SM which treats disability as a process of social exclusion (Chouinard et al., 2010). It assumes that limited ability is caused by both individual conditions (connected to a specific dysfunction) and those of the surrounding physical and social environment creating the restrictions which occur in the PwD - environment (social and physical) relation. The GM has accepted a significant paradigm in that it treats needs connected to various types and degrees of disability not as "special" but as one of many which occurs in contemporary society. Universal design should therefore take the nature of these needs into account in universal design, in the creation of maximally accessible buildings, sites, and public services (Imrie, 2012; Zajadacz, 2014c; 2015). The central postulate is not to concentrate on "disabilities", but to focus on various social needs and adapt the geographic environment (social, as well as physical) accordingly. The presented disability models are connected to the various types of social relations that people with a disability have with society (Figure 1): from exclusion through integration to inclusion (Zajadacz, 2015).

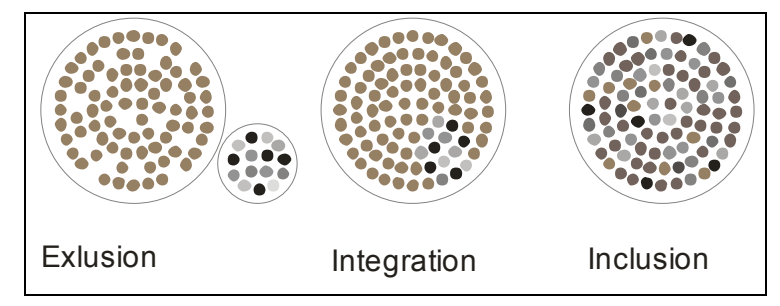

Figure 1. Models of social exclusion, intergration, and inclusion of people with disabilities. Source: Schrader (2012). 


\section{The Main Aim, Research Methods and Hypothesis}

The tourism industry service for the disabled is one of the realities of the future tourism and new tourism. But the implementation of the accessible tourism concept depends on the competence and attitudes of staff towards guests with disabilities. The aim of the research was - above all - to provide knowledge useful in the process of improving educational programmes in the field of tourism and recreational studies, and in particular in the field of organising accessible tourism. The first stage in the process was to determine the current knowledge and opinions of students with reference to this issue. The main aim of this study was to identify the current attitudes of future tourism employees towards disabled tourists and the following hypotheses were assumed:

$\mathrm{H}_{1}$ - Future employees in tourism services are predominantly open and have a positive attitude towards clients with disabilities;

$\mathrm{H}_{2}$ - The main factor affecting reluctance to enter into contact with disabled people is a lack of experience and therefore insufficient knowledge of conditions affecting the behaviour of disabled people, inadequate skills regarding how to react in new situations which result in a sense of discomfort and unease.

Research was carried out at the Adam Mickiewicz University in Poznań (UAM, Poland) and the National University in Irkutsk ((ИГУ, Russia) amongst bachelor degree students of tourism and recreation in May 2013. The choice of the research area was determined by the huge dynamics of the development of tourism, in particular in the number of foreign tourists visiting Poland (Poznań) and the district of Irkutsk, located at Lake Baikal (Russia). Both destinations can be considered to be new and attractive from the perspective of foreign tourism development. With reference to the trends in the development of tourism from the point of view of personalization of services and paying increasing attention to the quality of such services (including accessibility to people with disabilities), it was important to identify the opinions of future tourism sector employees on the organisation of accessible tourism. The choice of dynamically developing tourist destinations located on two continents provided a broader insight into the studied problem, not only from European, but also from Asian perspective.

Students were interviewed "face to face" and asked to respond to survey questions where a range of possible answers were provided. The main section of the survey contained four questions regarding issues such as:

- Optimal ways to organise tourism products for people with a disability;

- Attitudes towards spending leisure time together with people with a disability;

- Specific requirements concerning the introduction of various types of improvements in tourism products aimed at people with a disability.

\section{Research Results}

\section{Polish Case Study}

In the study group, there were a total of 108 people aged $19-24$, ( $74 \%$ female, $24 \%$ male, and $2 \%-$ no data). The majority (57\%) declared that they had had some contact with people with a disability, most of whom were affected by a physical impairment, followed by mental illness then an auditory or visual dysfunction. About $21 \%$ of the participants stated a member of their family had a disability, physical impairment was the most common disability followed by a visual or auditory impairment or mental disorder. 
Considering how holiday breaks for people with a disability is organised within the context of the integration and exclusion models (trips organised separately for people with specific disabilities), the majority (94\%) of those questioned were of the opinion that there is no single universal solution. Such trips should be organised both together and separately, depending on the type and degree of disability as well as the expectations of the participants. A small number of survey participants (12\%) were strongly of the opinion that trips for the disabled should be organised separately, whereas $2 \%$ declared that trips should be organised for fully-abled and disabled people together, the remainder did not state an opinion on this issue.

The majority of students (57\%) expressed a positive attitude towards spending their leisure time with PwD. About $28 \%$ from the group surveyed stated the type of disability was insignificant, $15 \%$ claimed that they would spend time with blind people, $11 \%$ with people with a physical impairment, and $9 \%$ said that they would spend time with deaf people. Nearly $43 \%$ of the total group stated that they did not want to spend their leisure time with PwD, and 36\% of respondents overall declared that they felt a sense of discomfort, and did not know how to behave or react to the situation, or that the reason for their response was due to the needs of the person with a disability. A significantly smaller group (6\%) referred to the fact that PwD slow them down, which make sightseeing difficult, they feel frightened when they see a PwD, they are scared that such misfortune may happen to them or a loved one. Just $4 \%$ of students questioned responded that when they have some leisure time they just want to relax and are not interested in the problems of other people.

All those questioned see a need to introduce improvements increasing the accessibility of tourism for people with disabilities. The main solutions mentioned were technical (e.g., lifts, vehicles, accessible transport, and toilets) accounting for $91 \%, 49 \%$ of the group noted openness of society and attitudes of staff in customer service regarding the individual needs of $\mathrm{PwD}, 34 \%$ of those surveyed were of the opinion that clear information was necessary (including available entrances, stops, and accommodation). As PwD have very low incomes, a need for trips to be financially supported was noted by $21 \%$.

\section{Russian Case Study}

There were a total of 108 participants in the study (77\% female and $23 \%$ male) aged $19-24$. The majority stated that they had encountered people with a disability, the most common disability was physical, followed by a hearing impairment, then visual and mental disorders. About $17 \%$ of respondents said that a family member had a disability, mainly a physical impairment, but others were blind, deaf, or mentally ill.

Regarding attitudes towards principles of organising trips, the most common response (95\%) was that these should be organised both for mixed groups and for separate groups, as much depends on individual circumstances related to the type of disability. Nearly $11 \%$ were definitely in favour of mixed trips, fewer (6\%) supported the isolation model where trips are arranged for separate groups with different types of disability.

More than half $(56 \%)$ of those questioned willingly spend or would spend time with PwD, regardless of disability type ( $43 \%$ of overall responses), a smaller group indicated that they were willing to be with physically disabled people ( $8 \%$ ) and the lowest percentage $(2 \%)$ concerned spending leisure time with blind or deaf people. About $44 \%$ of respondents indicated a negative attitude in this field. The most common reason given being feeling self-conscious, a lack of knowledge and skills for how to react (16\%), followed by feeling frightened when seeing a PwD (8\%). A similar number (7\%) indicated a desire to rest and relax in their leisure time, these respondents were not interested in the problems of others, they also responded that they do not like PwD as they are very demanding. 
All those questioned recognised the need to introduce special facilities in holidays for people with a disability. The largest number of suggestions $(88 \%)$ in this field is related to technical issues such as lifts, ramps, easily-accessible vehicles, toilet facilities, and so on. Over half of the students also indicated the significance of the degree of openness of society and staff dealing with PwD in terms of respecting individual needs. Nearly half (43\%) identified financial support for holidays was a necessity, due to the low incomes of PwD. Furthermore, over a quarter (28\%) of participants noted the importance of clear information (including accessible entrances, public transport stops, and accommodation) in the development of accessible tourism.

\section{Discussion}

The answers provided by both the Polish and the Russian students concerning how holidays for the disabled are organised lead to the conclusion that there is no single optimal solution. Diversification of tourism products is desirable, taking into account the characteristics of tourism demand, and the degree and type of disability. Comparison of the analysed case studies against the presented disability models: medical, social, and geographical, supports the assumption of the geographical concept as optimal in the current period. Amongst the basic activities directed to increase accessible tourism for the disabled the following are deemed necessary:

(1) Removal of external barriers relating to technical facilities, raising awareness in order to improve social attitudes, including openness and flexibility in the search for optimal solutions of staff in relation to PwD;

(2) Taking the needs of the target group into account when developing a tourism product, considering the type of disability, low income levels or factors limiting perception in the tourism information sector.

The results of the analysis of the participants' answers regarding theoretical interpretations of disability have become the basis for the formulation of guidelines on action in the field of diversification of supply in the tourism market. These proposals include "specialist", "adapted", and "universal". The "core" of these actions is connected to the medical disability model and the need to create a "specialist supply" in tourism offers (e.g., stays at rehabilitation centres, workshops for PwD — often together with families and assistants). A further type of "adapted supply" reflects the social model of disability and covers a wide range of holidays, during which the product adapted to the needs of PwD should be necessary, requiring the support of the immediate social environment (e.g., the participants of the trip must agree to a slower pace when sightseeing, which is connected to mobility issues of wheelchair users). The "universal tourism supply" type reflects the GM of disability and is connected above all to guaranteed ease of access to tourist sites, building, and services and makes it possible for PwD to be independent.

\section{Conclusions}

The comparison of the results of the presented case studies permits general conclusions supporting the first hypothesis which is that an attitude of openness and a positive approach to future employees in the tourism services sector to the needs of tourists with disabilities currently exists. The second hypothesis is also supported. The responses of the survey participants—both from UAM and ИГУ—revealed that the main factor influencing a reluctance to enter into contact with $\mathrm{PwD}$ is a lack of previous experience resulting in insufficient knowledge on the aspects conditioning the behaviour of $\mathrm{PwD}$, and how to react in new situations, a 
feeling of anxiety and in some cases fear. This is an important finding which should be considered in educational programmes in tourism and recreation studies. It is vital to include subjects on providing appropriate customer service to tourists with disabilities, especially practical workshops where skills in this field can be gained and barriers were broken in relation to social attitudes or current stereotypes of specific types of disability.

The opinions of the students representing UAM and ИГУ concur regarding the need to apply the exclusion, integration, and inclusion models when creating a tourism product depending on the degree and type of disability as well as the individual expectations of clients. One problematic issue is the fact that over $40 \%$ of those surveyed do not want to spend their leisure time with $\mathrm{PwD}$, giving various reasons for this, one of which relates to the demanding attitudes of people with disabilities. Such attitudes, just as the attitudes of those in customer service towards people with a disability, can determine the degree to which social integration and accessible tourism are implemented.

The data discussed in this paper present only one perspective-opinions of students of tourism and recreation on organisation of accessible tourism. They are useful in the process of improving educational programmes in the field of tourism and recreation, and consequently they can help develop the qualifications of people working in the sector of tourist services. It is worth stressing however that activities intended to optimize solutions guarantying a better quality of services and accessibility of tourism to people with disabilities require thorough studies including — first of all — the opinions of the addressees of such changes (i.e. people with various disabilities) as well as the identification of opinions of representatives of the tourist sector.

\section{References}

Best, S. (2010). Leisure studies. Themes \& perspectives. London: SAGE Publications Ltd.

Buhalis, D., \& Darcy, S. (Eds.). (2011). Accessible tourism. Concepts and issues. Bristol: Channel View Publications.

Convention on the Rights of Persons with Disabilities. (2006). Retrieved from http://www.un.org/disabilities/convention/conventionfull.shtml

Chouinard, V., Hall, E., \& Wilton, R. (Eds.). (2010). Towards enabling geographies: "Disabled” bodies and minds in society and space. Surrey, England, Burlington, VT, USA.

Darcy, S., \& Pegg, S. (2011). Towards strategic intent: Perceptions of disability service provision amongst hotel accommodation managers. International Journal of Hospitality Management, 30, 468-476.

European Disability Strategy 2010-2020. (2010). New strategies for a barrier-free Europe COM (2010), 636, Brussels.

European Union, Facts and Figures. (2012). Retrieved from http://www.consilium.europa.eu

Lipp, E. (2015). Disability travel generates $\$ 17.3$ billion in annual spending. New Nationwide Research from Open Doors

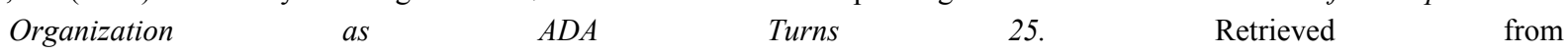
http://opendoorsnfp.org/wp-content/uploads/2016/03/ODO-Study-Press-Release-Final.pdf

Imrie, R. (2012). Accessible housing: Quality, disability and design. London: Routledge.

Oliver, M. (1996). Understanding disability: From theory to practice. Houndmills, Basingstoke: Macmillan.

Parsons, T. (1951). The social system. London: Routlage \& Kegan Paul.

Schrader, R. (2012). Barrierefreiheit als qualitätsund komfortkriterium im tourismus vorstellung desprojekts "reisen für alle". Deutsches seminar für tourismus (DSFT), Berlin. Retrieved from www.deutschland-barrierefrei-erleben.de/wp-content/uploads/2012/10/140124_dsft-visitberlin-markttag.pdf

World Health Organization. (2011). World report on didability. Retrieved from http://www.who.int/disabilities/world_report/2011/report.pdf

Zajadacz, A. (2014a). Nastawienie przyszłych pracowników sektora usług turystycznych do niepełnosprawnych klientów. Studia przypadku z Polski i Rosji. [In:] Seria Turystyka i Rekreacja-Studia i Prace, Bogucki Wydawnictwo Naukowe, Poznań, $30-43$. 
Zajadacz, A. (2014b). Accessibility of tourism space from a geographical perspective. Tourism, 24(1), 45-50.

Zajadacz, A. (2014c). Sources of tourist information used by deaf people. Case study: The Polish deaf community. Current Issues in Tourism, 17(5), 434-454.

Zajadacz, A. (2015). Evolution of models of disability as a basis for further policy changes in accessible tourism. Journal of Tourism Futures, 1(3), 189-202. 